\title{
MUERTE Y SUICIDIO EN LA OBRA DE PIERRE DRIEU LA ROCHELLE
}

Brigitte Leguen

UNED

"O mort je ne t'oublie pas. $O$ vie plus vraie que la vie. $O$ chose indicible qui est au-delà de la vie. Non pas au-delà, en-deça. C'est le noyau de mon être que je veux atteindre"!

Esta invocación a la muerte, a su propia muerte, puesto que el escritor se expresa en primera persona, está anotada en el diario de Drieu con fecha del 23 de octubre del año 1944. No es más que una de las numerosas alusiones a esta obsesiva idea que persigue al escritor y que el escritor a su vez persigue hasta convertirla en realidad, en acto. Drieu, quien decía poco antes de dar el paso definitivo: “J'aurais aimé à faire partie de cette confrérie des suicidés. Tout compte fait, c'est une doble confrérie" ${ }^{2}$, dedica a la reflexión sobre la muerte libremente escogida uno de sus últimos escritos titulado Récit secret.

Más indirectamente, a través de la ficción, persigue la misma meditación aunque esta vez sin nombrar a la muerte y reemprende con el protagonista Dirk Raspe la reflexión nunca abandonada pero nunca tan precisamente conseguida como en su última novela cuyo título completo será Mémoires de Dirk Raspe?

1 Pierre Drieu la Rochelle, "Journal 1944-45" in Récit secret, Paris, Gallimard, 1951, p.56

2 Pierre Drieu la Rochelle, op. cit. p. 76

3 En su novela $L$ 'homme a cheval Drieu escribe: "L'homme ne naît que pour mourir et il n'est jamais si vivant que lorsqu'il meurt, mais sa vie n'a de sens que s'il donne sa vie au lieu d'attendre qu'elle lui soit prise".

"Rabi", en un artículo titulado "Pour un portrait de Drieu la Rochelle" en Esprit. 
Esta última novela de Drieu la Rochelle, inacabada y publicada mucho después de su muerte (el autor se suicida el 15 de marzo de 1945 y el libro sale a la venta en el año 1966, o sea veinte años más tarde) fue escrita e ideada justo antes de su primer intento de suicidio, en el mes de agosto de 1944. Hasta sus últimas horas de vida el escritor trabaja en su obra, o al menos piensa en ella como en el único proyecto literario que le queda. El 13 de marzo, dos días antes de darse muerte, comenta en su diario:

"Je n'ai plus travaillé a Dirk Raspe depuis la fin de décembre. Trop inquiet, trop dérangé, trop dégoûté. A quoi bon faire de la littérature même comme celle-ci, puisque j'attends les huns".

Pero añade una última anotación:

"Je vais peut-être me remettre aux dernières parties de Dirk Raspe par manie d'achever quelque chose de commencé". 4

Juntamente con la novela, Pierre Drieu la Rochelle escribe un texto corto y denso titulado Récit secret, publicado en 1951, con una tirada de 500 ejemplares en "Arts et métiers graphiques"s. Dato curioso, la edición original de aquel ensayo se llevó a cabo en el otoño de 1950 en la revista Sur dirigida por Victoria Ocampo, gran amiga del autor desaparecido. El mismo texto vuelve a ser publicado por la Editorial Gallimard el mismo año 1951 junto con el diario de 1944-45 y un breve manifiesto titulado "Exorde". Nos basaremos en estos textos para considerar la cuestión de la fascinación por el suicidio y la muerte en Drieu, cuestión que se ofrece como una auténtica constante de la novela drieuniana y como eje de todo su recorrido existencial ${ }^{6}$.

$n^{\circ} 210$, enero de 1954, p. 140, escribe: "A tout instant dans l'oeuvre de Drieu, le personnage trahissant sa fonction de créature franchit l'écran d'encre et de papier qui le sépare de l'auteur. Ou bien, c'est l'auteur lui-même qui effectue l'opération inverse, pénétrant dans l'univers imaginaire, prenant la place du héros, revêtant son armure. Dès 1927 , Benjamin Crémieux pouvait donc dire sans se tromper à Drieu: vous n'êtes pas un romancier...Toute l'oeuvre de Drieu, préfaces y comprises, est la confidence perpétueliement reprise de son personnage".

4 Pierre Drieu la Rochelle, "Journal 1944-45", op. cit. p. 86

5 J-P Bonnafous, "Notes sur les inédits", en Defense de l'Occident, febrero-marzo 1958, número especial titulado Drieu la Rochelle, témoignages et documents, pp. 129-135

6 "Rabi", "Pour un portrait de Drieu la Rochelle", loc. cit. p. 140 
De estos textos, sólo uno es estrictamente novelesco. Es a través de la ficción como el autor intenta dar a conocer sus últimas reflexiones mediante la voz de un narrador en primera persona. La anécdota recoge todo el paulatino proceso de iniciación de un artista aún inexperto, cuyo modelo inicial resulta ser la vida del pintor Van Gogh que también acabó suicidándose. El paso por la prueba de la pobreza, el sexo, el misticismo y el arte introduce gradualmente el debate entre la vida y la muerte, la destrucción y la creación, que marcó tanto la totalidad de la obra de Drieu como su propia vida.

En cuanto a los otros textos agrupados bajo el título genérico de Récit secret, escapan aparentemente al dominio de la ficción y nos remiten hasta cierto punto a los azarosos márgenes de la autobiografía. En efecto, el mismo título de Récit secret delata la manipulación del proyecto y de su producto, puesto que carece por completo del carácter secreto que se le atribuye al ir dirigido a un público, a un lector, en un momento clave en el que el escritor necesita explicarse y justificarse, no tanto frente a sus contemporáneos sino más bien frente a la posteridad, frente a ese futuro al que decidió no pertenecer ${ }^{7}$.

La autobiografía, tentación constante de este hombre de letras ${ }^{8}$, es menos que un género con sus normas, un límite al que se tiende, un umbral al que uno se asoma. Ningún relato puede pretender la sinceridad absoluta que es producto de la confesión y del auténtico secreto. En la autobiografía, al elaborar un texto en función de un posible lec-

7 Pierre Drieu la Róchelle, "Journal 1944-45", op. cit. p. 48: "Le journal c'est la lâcheté de l'écrivain. C'est le comble de la superstition littéraire, du calcul sur la postérité".

8 J. Bersani, M. Autrand, J. Lecarme, B. Vercier, La litterature en France depuis 1945, París, Bordas, 1970, p. 291: "L'autobiographie est moins un genre avec ses règles qu'une limite vers laquelle on tend. Aucun récit ne peut prétendre a la sincérité absolue de la confession. L'autobiographie qui implique une élaboration du récit réintroduit la fíction par le seul fait qu'elle crée une figure fictive de la personnalité.

Según Jean Benoît Puech, "Du vivant de l'auteur", en Poétique, n 63, septiembre 1985, p. 280, es en el siglo xviı en Francia cuando surge la figura del hombre de letras. Dice J-B. Puech "En 1780, deux ans après la mort de Voltaire et de Rousseau, alors que Diderot et d'Alembert sont encore vivants, l'expression "homme de lettres" a pris un sens moderne, celui d'un état dans la société, celui d'un métier".

Dentro de lo que se ha clasificado como perteneciente al género autobiográfico, Romera Castillo en La literatura autobiográfica como género literario, Colegio Universitario de Soria, 1980, pp. 50-54, considera como tal las obras escritas en la época de madurez del escritor que sirven para explicar, justificar o testimoniar, aportar nuevos datos de sí mismo y de su entorno.

G. May en L'autobiographie, París, P.U.F. 1979, pp. 60-65, refiriéndose al plano de la enunciación, señala las dos características fundamentales del estilo autobiográfico. Son las siguientes: el relato en primera persona y el orden cronologico del relato.

Sobre la cuestión de la relación del escritor persona-personaje a la obra véase Philippe Lejeune, Le pacte autogiographique, París, Seuil, 1975 y Philippe Lejeune, Je est un autre, París, Seuil, 1980. 
tor crítico, el autor reintroduce la ficción, crea una figura ficticia de la personalidad, instituye una presencia mítica del escritor. Dice G.W. Ireland que "En cuanto el hombre trata de narrarse, de decir la verdad sobre sí mismo, se somete, según Valéry a exigencias como artista. ¿No es en este sentido en el que Gide también insistía en que "La hipocresía es una de las condiciones del arte?" (O.C.IV.192). Por su misma naturaleza, el arte es transcripción de la vida a un registro diferente de la verdad, tal al menos como concebimos la verdad fuera del arte" 9 .

Durante estos últimos veinte años, los estructuralistas se distancian del método biográfico en crítica literaria y rechazan cualquier vínculo entre el autor y su obra. Sin embargo, sería vano considerar como clausurado el tema biográfico. Hoy en día, el autor aparece a los ojos de la crítica como producto a la vez de la obra y de los múltiples discursos que la acompañan'0.

Desde principios del siglo XX, como señala Thibaudet, los llamados "romans de l'écrivain" se multiplican". Gide, con su novela Les faux monnayeurs, será el ejemplo más convincente de esta forma de escritura tan característica de este siglo.

Esta confusión, o mejor esta amalgama entre hombre de letras y hombre de acción "engagé" como se dijo luego, y entre escritor y hombre (el ejemplo de Michel Leiris es quizá el más significativo) ${ }^{12}$ es el efecto de un estado existencial que irá cobrando mayor vigor a medida que pasan los años.

Los valores están en crisis desde la primera guerra mundial. El bien del hombre en su relación al mundo deja de constituir un hito incuestionable y la verdad se convierte en lo que uno mismo concibe: "A chacun sa vérité". La famosa encuesta de los surrealistas:"Pourquoi écrivez-vous?" empieza a turbar los espíritus y a despertar las dudas después de 1930.

Drieu aparece en este conjunto como un autor bisagra y participa

" G. Poulet (ed), Los caminos actuales de la critica, Barcelona, Planeta, 1967, "Gide y Valéry precursores de la nueva crítica" pp. 45-56.

Escribe también G.W. Ireland, p. 53 "La obra no contiene el retrato de su autor, sino que es este retrato mismo. Lo que la crítica tiene que buscar no es al hombre "en" la obra, sino que debe reconocer al hombre "de" la obra".

10 Jean-Claude Bonnet dice: "Il apparait aujourd'hui que l'auteur est produit à la fois par l'oeuvre et les multiples discours qui accompagnent celle-ci. Quant à l'être de chair (et non de papier) qui écrit, il ne cessera jamais d'entretenir une curiosité fétichiste qui touche au plus secret de la littérature et de l'écriture dans son vertige énigmatique", "Le fantasme de l'écrivain" en Poétique, $n^{\circ}$ 63, septiembre 1985, p. 260.

11 A. Thibaudet, Histoire de la littérature francaise de 1789 d nos jours. París, Stock, 1936.

12 Michel Leiris tambien manifiesta esta necesidad de actuar tan fuerte en Drieu. Leiris quiere, con su libro L'Age d'homme hacer un libro que sea un acto. 
en diversas corrientes. La última parte de su obra coincide con los autores de la segunda generación, pero su ideología es el resultado de los ideales surgidos a raíz de la primera guerra mundial. Más que autor "engagé" él se considera "homme d'épée"13 y su sistema de valores está dominado por un ideal aristocrático en plena decadencia. La muerte es para él como para Cioran, el destino que escogen los héroes y los justos. Escribe Cioran:

\begin{abstract}
"Lorsqu'on est jeune, on se cherche des héros: j'ai eu les miens: Henri de Kleist, Caroline de Guenderode, Gérard de Nerval, Otto Weininger... Ivre de leur suicide, j'avais la certitude qu'eux seuls étaient allés jusqu'au bout, qu'ils tirèrent dans la mort la conclusion juste de leur amour contrarié ou comblé, de leur esprit fêlé ou de leur crispation philosophique... Hors du suicide point de salut. Chose étrange, la mort, quoique éternelle, n'est pas entrée dans les moeurs: seule réalité, elle ne saurait devenir vogue. Ainsi, en tant que vivants, nous sommes tous des arriérés..."14
\end{abstract}

Cioran publica su Traité de décomposition en 1949 y sin embargo no se aleja mucho de lo que Drieu piensa y expresa unos años antes. Para los dos la muerte se ofrece como "la seule réalité" al igual que para el personaje Dirk Raspe:

\begin{abstract}
"Qu'on éclate, qu'on en finisse j J'étais sûr, appelant si fort une fin, que ce n'était pas une fin, que toute fin est un commencement. J'étais bien sûr de ma vie éternelle. Pas une sale petite immoralité, identité personnelle. Comme c'est bête; Quel intérêt y a t-il à Dirk Raspe? Ce qui est intéressant dans Dirk Raspe c'est ce qui n'est pas Dirk Raspe, et ce qui est plus Dirk que Dirk. J'etais bien sûr que la vie est éternelle et je pressentais ce que depuis j'ai compris, senti si bien, si atrocement, si délicieusement, qu'au sein de la vie éternelle, il y a un noyau qui n'est plus la vie, qui n'est plus l'Etre, qui est autre chose. Peut-être à jamais inatteignable par nous: l'indéterminé, l'ineffable"'s.
\end{abstract}

13 Pierre Drieu la Rochelle, "Péroraison" en Recit secret, op. cit. pp. 97-98. Dice Drieu: "C'est le rôle de l'intellectuel, du moins de certains d'entre cux, de se porter au-delà de l'évènement, de tenter des chances qui sont des risques, d'essayer les chemins de l'histoire".

14 E.M. Cioran, Précis de décomposition, París, Gallimard, 1949, pp. 231-232, “Mes héros”.

15 Pierre Drieu la Rochelle, Mémoires de Dirk Raspe, París, Gallimard, 1966, p.168 
Pero Dirk Raspe hace como Drieu, más y mejor que Drieu la experiencia de la fe: "Je croyais que tout se passe dans le coeur et que ce qu'on appelle Dieu est le noyau de ce coeur"16.

Dirk Raspe es una ficción de libertad que Drieu no consigue para sí mismo. Dice el autor en su diario: "Je continue à écrire Dirk Raspe où je trace une nouvelle image de ma liberte" 17 .

El escritor en cambio se rebela contra su ineptitud frente a la vida, contra la fatalidad que le persigue (o que él vive como una persecución), mientras el héroe Dirk Raspe acoge su destino y consigue sublimar su sufrimiento en la pintura y en los demás. Dirk Raspe es el único personaje de Drieu realmente capaz si no de amor al menos de compasión hacia los demás, de esta fraternidad de la que el hombre real reniega y requiere a un mismo tiempo.

Drieu, siempre ambiguo en su discurso y contradictorio en su pensamiento, sueña con ser otro hombre, mientras Dirk Raspe sólo busca encontrarse a sí mismo. Dice Drieu con nostalgia:

\begin{abstract}
“Je voulais être un homme complet, non pas seulement un rat de cabinet, mais aussi un homme d'épée, qui prend des responsabilités, qui reçoit des coups et en donne. Certes, mais il y avait là autant de vanité que de courage, et je regretterai toujours de n'avoir pas rempli ces derniers ans le poste de dandy, l'homme rigoureusement non conformiste, qui se refuse à toutes les sottises courantes dans un sens et dans l'autre, et qui manifeste discrètement mais fermement une sacrilège indifférence". 18
\end{abstract}

Es de notar cómo el escritor califica la indiferencia de "sacrílega". Lo que sí comparten el personaje Drieu de Récit secret y el personaje Dirk Raspe, es esta terrible fatalidad del yo que les lleva a reducir la visión del mundo, la visión universal, a una visión siempre subjetiva; el mismo egotismo les une ${ }^{19}$.

Drieu asume plenamente su fraternidad con los héroes de sus novelas, y admite que son el portavoz de su angustia:

"Ce que j'apelle héros de roman, c'est le moyen par quoi le romancier qui d'ordinaire écrit ses meilleurs livres lorqu'il n'est plus jeune,

16 Pierre Drieu la Rochelle, op.cit. p. 132

17 Pierre Drieu la Rochelle, "Journal 1944-45" en Récit secret, op.cit. p. 62

18 Pierre Drieu la Rochelle, "Journal 1944-45" en Récit secret, op.cit. p. 82

19 Pierre Drieu la Rochelle, Mémoires de Dirk Raspe, op.cit. p. 200. 
met en scène les parties encore vives de lui-même, en même temps que celles qui son mortes. C'est le lieu merveilleux ou confluent l'observation et la création, la mémoire et le rêve, le réalisme et l'idéalisation. Le regret et l'espoir, l'illusion et la vue froide"20.

Tal y como Drieu concibe la novela, se define como una totalidad que une a la ficción con la reflexión y el-pensamiento teórico. El 17 de enero confiesa en su diario: "J'étais dégoûté de Dirk et de moi-même dans Dirk et de Dirk dans moi-même".

Se expresa bien aqui la imbricación entre el personaje Drieu y el protagonista Dirk, entre el nivel homodiegético y el nivel heterodiegético. El escritor se presta y casi se hace cómplice de lo que Daniel Oster denomina "el tradicional espacio emblemático del escritor"21.

Julien Hervier, en un artículo titulado "Drieu la Rochelle, ou le roman inachevé" comparte esta opinión que hemos insistentemente recalcado, entre ficción y vida:

“Il faut avouer que Drieu, qui n'écrit pas par divertissement ou futilité mais pour répondre a une exigence absolue a peut-être choisi la seule solution authentique. Le suicide de Drieu est substitutif de celui du héros, mais l'inverse aurait pu également être vrai. La catharsis n'est pas une invention d'esthète, le journal inédit porte les traces de l'atroce imbrication entre la difficulté à survivre et le dégoût de l'oeuvre"22.

Nos queda pues por ver qué relaciones se establecen en el texto entre el relato autobiográfico y las "mémoires".

El primer vínculo que creemos conveniente destacar entre las obras propuestas como corpus radica en una necesidad esencialmente filosófica: la conciencia de la irremediable subjetividad del hombre frente a lo universal. El hombre Drieu no puede liberarse de las circunstancias peculiares que le rodean y le condicionan. Asume su estado de hombre de letras hasta el final y expresa los motivos voluntarios que le impulsan a asociar reflexión y ficción en este último período de su vida:

20) Julien Hervier, "Drieu la Rochelle ou le roman inachevé" en Magazine littéraire, n" 143. 1978 , p. 25

21 Daniel Oster, Passage de Zénon, París, Seuil, p. 228

22 Julien Hervier, loc. cit. p. 27 
"La littérature, c'est la recherche et le culte du concret, du particulier; certes, par ailleurs, cela comporte une vue de l'universel. C'est Dieu dans ses oeuvres, c'est le Dieu démiurge et créateur. C'est pourquoi cette reprise de la littérature et de mon journal, après une telle expérience [el primer suicidio] en dit long sur mon incapacité spirituelle. Et il est vrai qu'une des nombreuses raisons pour lesquelles je voulais casser la corde, c'étais que je sentais mon impuissance à dépasser le simple pressentiment de la conquête intime"23.

Drieu experimenta la necesidad de la ficción como una limitación a la que no puede escapar y se resiste a reconocer lo que los existencialistas conciben como el principio primero "il n'y a de vision du monde que particulière". Esto explica cómo en la generación siguiente el pensamiento existencialista encontrará un importante medio de difusión en la novela. Drieu, desbordado por su propia historia, dibuja la de su protagonista que emblemáticamente utiliza dos tipos de lenguajes para expresarse, dibujando y escribiendo lo que siente y lo que ve. Dirk Raspe es como Drieu el testigo impotente de un mundo en el que se justifica continuamente su ineptitud a vivir pero que encuentra, al menos de forma temporal (se trata de una historia inacabada), su salvación en la creación de formas. El arte salva a Dirk mientras que la literatura no consiguió apartar a Drieu de su proyecto final.

El libro Mémoires de Dirk Raspe, se divide en cuatro partes que coinciden con cuatro hitos de una iniciación, la de un joven artista solitario que descubre su auténtica vocación a través de sus encuentros con una serie de personajes y con la pintura.

El hecho de que la novela quede inacabada nos impide evidentemente conocer el final que el escritor le tenía asignado al protagonista. Al tratarse inicialmente de un personaje calcado de la vida real del pintor Van Gogh, podemos especular que concluiría por el suicidio, pero nada nos permite asegurarlo. Preferimos ver en este carácter inacabado un signo muy en adecuación con la postura vital del autor que siempre se identifica, como dice Mac Orland como "l'homme de l'inachèvement; l'homme qui nourrit pour l'inachèvement, pour l'échec un goût pervers et, comme il le dit lui-même, quasi mystique" 24 .

Otro crítico subraya también la concordancia existencial entre la estructura formal del relato y la postura personal del autor. Lo inacabado, según este mismo crítico, tiene un carácter emblemático y pone

23 Pierre Drieu la Rochelle, "Journal 1944-45" en Récit secret, op.cit. p. 52

24 P. Mac Orland, "Drieu la Rochelle", en Nouvelle revue française, $\mathrm{n}^{\circ} 12$, diciembre de 1953 , p. 1080 
en relación un vivir con un decir: "Sa forme romanesque, qui est une forme sens, produit de l'homogénéité du dire et du vivre-dire"2s.

Drieu opta por finalizar la cuarta parte de la novela con una doble ruptura del personaje ${ }^{26}$, con la fille Tristesse y Catherine que encarnan la doble vertiente de la figura femenina deseada, la primera depravada y lasciva, la segunda casta y pura. Este final deja paso a un nuevo encuentro de Dirk Raspe con la nada, final muy significativo si se piensa que la palabra "néant" es la última del libro y la que pone punto final a toda la obra de ficción del autor:

"Mais à quoi bon raconter une rencontre nouvelle avec le néant"27.

El libro está perfectamente dividido en lo que figuran como cuatro etapas de la vida recordada del pintor Dirk Raspe; la juventud en un pueblo apartado de Inglaterra en casa del pastor Heywood, el descubrimiento del sexo y de la pintura en Londres en casa de mrs. Porlock y en la tienda de mr. Mack, la experiencia mística de la pobreza en Hoeuvre en Holanda, y la experiencia de la creacción en La Haya.

En cada una de estas cuatro partes dos o tres personajes tienen como función el marcar los hitos necesarios al aprendizaje. Drieu renuncia a sus procedimientos habituales de escritura al emplear la primera persona, al describir detalladamente a sus personajes y al renunciar al medio parisino y mundano que sirvió de marco a varias de sus novelas ${ }^{28}$.

El propósito ideológico de la novela discurre en torno a los personajes introductores de los "abismos" a los que se asoma el protagonista:

Julien Hervier, "Drieu la Rochelle ou le roman inachevé", loc. cit. p. 25

26 Drieu emplea dos modelos para concluir sus novelas, como lo recalca nuevamente J. Hervier: rupturas o suicidios (alusivos o realizados); Puede existir también una combinatoria de los dos finales.

Pierre Drieu la Rochelle, Mémoires de Dirk Raspe, op.cit. p. 243

28 Bernard Vorge, "Drieu la Rochelle ou le sacrifice", en Defense de l'occident, loc. cit. pp. 58 y 60: "Ses personnages sont construits de traits simplifiés à la manière des masques antiques: ce sont des types, des idées générales réalisées"

"Drieu a fait de tous ses romans des sortes d'essais mis en scène où les personnages se heurtent aux parois de leurs cerveaux et de leurs corps pour tenter d'en trouver l'issue, des dialogues infinis ou les êtres se martyrisent aux idées". 
“Tout ce qui m'attirait dans la vie, c'était ses abîmes par où elle s'ouvre sur ses profondeurs et ses au-delà. Auprès de Robert Heywood, j'avais été bien près de croire que son abîme était le seul. Et pourtant, il y avait aussi l'abîme de Cyril, et dans Londres l'abîme des couleurs. Ces abîmes me paraîssaient tout a fait contraires et inverses. Or ici, dans cette chapelle, pendant ces messes où n'assistaient que quelques vieilles silhouettes, $\mathrm{j}$ 'entrevoyais soudain un accord inattendu entre la mystique de Robert et celle de Cyril"29.

Profundidades y límites atraen a Dirk Raspe irresistiblemente:

"Me perdre, m'oublier, voilà ce que je voulais... me perdre en allant jusqu'au fond de la perte de ces êtres qui s'engouffrent par une fissure entre ce qui est homme et ce qui est animal"30.

"L'extrême horreur est une extrêmité, et de quelque façon qui dit extrêmité dit grandeur"3i.

La necesidad de alcanzar el fondo se materializa en la tercera parte de la novela con el deseo de bajar a la mina:

"Pourquoi voulais-je descendre dans la mine? Pour y voir comme sur la route, dans la rue, dans les maisons, de mes deux vues, d'une part le combat de la lumière et de l'ombre et d'autre part le coeur des hommes et son énigme" 32 .

El paisaje a partir del final de la tercera parte deja de tener un carácter abismal. El protagonista cambia de visión y dirige su mirada hacia la llanura:

Pierre Drieu la Rochelle, Mémories de Dirk Raspe, op.cit. p. 66

Ibidem, p. 112

P. Drieu la Rochelle, op. cit. p. 79

32 P. Drieu la Rochelle, op. cit. p. 132 
"La plaine était belle. Maintenant je regrettais de n'avoir pas joui davantage de cette plaine, de l'avoir négligée, suspectée, refusée. Quand même la plaine existait comme le pays de la mine" ${ }^{33}$.

Existen, decíamos, personajes-abismos, hombres y mujeres: los hermanos Robert y Cyril, la fille Tristesse, Sybil, Barbera, cuya decadencia física funciona como acceso a la belleza:

"J'ai aimé toute laideur avec une soumission entière pour la beaute" ${ }^{\text {".4. }}$.

Las mujeres bellas en cambio, Evelyn y Catherine, solo inducen al vacío y al engaño, quizá porque el protagonista sólo entiende la realidad a través del sufrimiento y de la miseria:

"Pour moi, il n'y avait aucune réalité en dehors de la souffrance et de la misère" 35

Como Drieu, Dirk Raspe no soporta lo que no expresa su propio sufrimiento:

"L'éternel hurlement de l'égotisme montait du fond de mon coeur: pourquoi n'est-il pas comme moi? Comment peut-on être si différent de moi? Est-ce qu'il y a de la pensée vraie, des lignes de couleurs vraies en dehors de ma souffrance, de ma lenteur? ${ }^{36}$.

Dirk Raspe lleva como Drieu un infierno dentro de sí mismo:

33 P. Drieu la Rochelle, op. cit. p. 167

34 P. Drieu la Rochelle, op. cit. p. 36

35 P. Drieu la Rochelle, op. cit. p. 119

36 P. Drieu la Rochelle, op. cit. p. 200 
'“J'avais toujours eu mon enfer à moi: Dieu savait quelle rancoeur, quelle bouderie m'avait jeté d'Evelyn sur Sybil et de Londres à Hoeuvre"37.

Dirk Raspe en su viaje en busca de sí mismo encuentra continuamente imágenes de muerte pero no sucumbe. La etapa en el pueblo minero coincide con el encuentro más real con la enfermedad y la muerte, pero la estancia en Londres y en La Haya deja vislumbrar otras formas de muerte, ya no física sino espiritual y artística, hasta despertar lo que Drieu llama "un sentiment profond de la décrépitude des choses" 38 .

Como Dirk Raspe, Drieu intenta aclarar los motivos de su conducta, pero con una distancia mayor aparentemente debido a la falta de ficción y al carácter extremadamente doloroso de la introspección que lleva a cabo. Dice Drieu: "Il n'y avait qu'un moyen de me guérir de la perte que je faisais de moi et de tout en rien, c'était de me perdre absolument" 39 .

Como Dirk, también busca la desmesura y sueña con la eternidad:

"Ma solitude spontanée devenait une mise hors la loi-ainsi s'accomplissait de façon imprévue -et outre mesure, ce qui m'émerveillait, car j'ai toujours été favorable a la démesure- mon voeu secret d'être privé de tout et arraché à tout" "⿻丷".

En el secreto de las memorias, aunque claramente se dirijan a un lector, igual que en el secreto del relato autobiográfico, se afirma la misma negación del hombre que une a los dos protagonistas. Los abismos de uno son los abismos del otro y juntos padecen la misma dolorosa sensación de lo que se dio en llamar "l'étrangement".

No creemos que el libro Mémoires de Dirk Raspe sea un "roman métaphysique" que intente introducir la reflexión filosófica como lo hicieron Simone de Beauvoir, Camus o Sartre. Dirk Raspe se asoma a un abismo que sólo le pertenece y que está inscrito en su historia per-

37 P. Drieu la Rochelle, op. cit. p. 202

38 Pierre Drieu la Rochelle, Récit secret, p. 38

39 P. Drieu la Rochelle, op. cit. p. 24

40 P. Drieu la Rochelle, op. cit. p. 28 
sonal, irrepetible y por ello mismo, trágica. Paralelamente, Drieu reivindica el carácter individual de su vacilación. No nos ofrece un tratado de la desesperación sino una reflexión personal sobre uno mismo. La soledad de Drieu y la de Dirk no implica como en Sartre o en Camus la ruptura, la renuncia a las esperanzas morales establecidas. Drieu tampoco es capaz, como Céline, de utilizar su desesperación para convertirla en motor de su obra. Por ello, Drieu sigue pensando hasta el final que ha fracasado puesto que no cree en un nuevo orden de valores. Padece dolorosamente la incertidumbre del hombre moderno pero sigue aspirando a un destino heroico. En este panorama, el suicidio parece el único acto con cierta grandeza. Otro de los personajes de Drieu, el Alain de la novela Feu follet afirma lo mismo:

"La destrucción es el recurso de la fe en la vida; si un hombre pasado los dieciocho años, llega a matarse, es que posee cierto sentido de la acción.

El suicidio es el recurso de los hombres cuyos resortes ha corroído la herrumbre, la herrumbre de lo cotidiano. Nacieron para la acción, pero han postergado la acción..."41.

Drieu, como sus personajes se niega a pertenecer a la masa, "la foule". A medida que pasan los años aspira más y más a deslindarse, a pertenecer a una élite, y al fracasar, reclama la muerte ${ }^{42}$. Dirk Raspe no llega a este extremo pero no intenta acaparar su parte del amor, del éxito, de la vida en general. Recibe el sufrimiento y la desesperanza casi como un don de Dios y como Baudelaire piensa:

"Je sais que la douleur est la noblesse unique" $"$.

41 P. Drieu la Rochelle, El fuego fatuo, Madrid, Alianza Editorial, 1975; trad. Emma Calatayud, p. 122. Primera edición francesa, París, Gallimard, 1931.

42 Pierre Drieu la Rochelle, "Exorde" en Récit secret, París, Gallimard, 1951, p. 99: "Je réclame la mort".

43 Charles Baudelaire, Les Fleurs du mal, París, 1861.

Dice Pol Vandrome en su libro titulado Drieu la Rochelle, París, Ed. Universitaires, "Classiques du XX"siècle, 1958, p. 79: "Avec Drieu, le romantisme remonte a sa source baudelairienne: de geignard, il devient lucide en s'avouant non plus comme l'inaptitude de l'homme au bonheur, dans un temps déterminé, et à cause de ce temps, mais comme l'inaptitude même à la vie. Entre les héros de Drieu et le pélerin-pénitent de La chûte de Camus, la distance ne se réduit-elle pas à presque rien? De ce bistrot d Amsterdam et des bars élégants de l'entre deux guerres, n'est-ce pas la même fumée, le même accablement qui monte?". 
Dirk Raspe no busca soluciones, ni siquiera intenta encontrarlas y se limita a ser un "tâtonnement de la vie",4, un intento del escritor en reconstruir una vez más, la última, el camino de la descomposición.

Cioran, pensador de la descomposición, consigue abarcar, sin que se traicione el pensamiento de Drieu en vísperas de su suicidio, el sentir de un escritor condenado por traidor pero íntimamente traicionado a su vez por unos ideales contradictorios e inadecuados. Rechazado, aislado, vencido en todos los terrenos donde pretendió actuar, Drieu escogió la única realidad que le quedaba, la muerte.

“On peut classer les hommes suivant les critères les plus capricieux:
suivant leurs humeurs, leurs penchants, leurs rêves, ou leurs glandes.
On change d'idées comme de cravates; car toute idée, tout critère vient
de l'extérieur, des configurations et des accidents du temps. Mais il y a
quelque chose qui vient de nous-mêmes, qui "est" nous-mêmes, une
réalité invisible, mais intérieurement vérifiable, une présence insolite
et de toujours, que l'on peut concevoir à tout instant et qu'on n'ose ja-
mais admettre, et qui n'a d'actualité qu'avant sa consommation: c'est
la mort le vrai critère...".s

44 P. Drieu la Rochelle, "Journal 1944-45" en Récit Secret, p. 64

45 E. M. Cioran, Précis de decomposition, París, Gallimard, 1949, p. 20 